International Journal of English Literature and Social Sciences
Vol-6, Issue-2; Mar-Apr, 2021
Journal Home Page Available: https://ijels.com/
Journal DOI: $10.22161 /$ ijels

\title{
Teaching of English Composition into Perspective
}

\author{
Dr. Adil M. Jamil
}

Mazaya University College, DhiQar, Iraq

Received: 20 Jan 2021; Received in revised form: 03 Mar 2021; Accepted: 25 Mar 2021; Available online: 21 Apr 2021

(C)2021 The Author(s). Published by Infogain Publication. This is an open access article under the CC BY license

(https://creativecommons.org/licenses/by/4.0/).

\begin{abstract}
This study is designed to gauge the effectiveness of methods used in writing classes at our regional universities, in comparison to the current methods commonly recommended by specialists and used at most American universities. The data is collected as follows. First, an informal survey was conducted with students who had already completed two writing courses, and various samples of corrected student writings were examined. Second, several interviews were held with a considerable number of writing instructors working at both public and private universities, and their writing syllabi were carefully studied. Data collection focused on the methods and strategies in effect; such as the number of students enrolled in each section, steps of writing taught, instructor responses, documentation of written pieces, textbooks, and grading procedures. The study reveals a number of weaknesses in need of urgent attention and offers suggestions and recommendations to help improve the teaching of English writing in regional universities.
\end{abstract}

Keywords - prewriting and drafting, revision, documentation, writing handbook, teacher responses, grading.

\section{INTRODUCTION}

\section{The Importance of Writing}

Writing, as a skill, plays an important role not only in composition classes and workshops but also in the teaching -learning process as a whole. Except for a few cases, writing is used as a means for measuring student proficiencies in almost all other university courses. Added to this, writing courses help enhance students' critical thinking, and widen their perspectives about the world. Considering this importance, the overwhelming majority of American universities require average and above average students to enroll in two writing classes totaling at least six credit hours for the completion of any bachelor's degree program. As well, poorly skilled students are often required to take nine credit hours in writing, such as remedial, basic, and intermediate composition. Even the above average students, who score higher grades on their placement tests, are often advised to take Intermediate Composition and Advanced Composition, to further hone their writing skills. By contrast, in many regional universities, the reality is different. University students are required to take one or, in rare cases, two composition classes in their mother tongue, Arabic, and students majoring in English language and literature are required to take two courses: Basic Writing and Essay Writing, presumably equivalent to Composition 101 and 102, or basic and intermediate writing courses. This sounds reasonable, but when examining student proficiency in writing, one may notice that the outcomes do not match the objectives - the improvement of writing skills-as listed in writing course syllabi. Student writing skills often remain the same after the completion of the required courses, except for a few instances of notable progress. Such a reality calls for an urgent investigation of the current situation, the methods and approaches in use, and recommendations for improvements to the teaching of writing.

\section{Data Collection}

The data in this study were mostly collected through informal surveys on students' learning experiences and students' ideas the about methods and behavior of writing instructor. The surveys were mostly done on students who had already taken and finished writing courses. In addition, 
information was elicited through careful examination of a considerable number of writing syllabi and university study plans. As well, a huge number of student corrected writing samples were carefully inspected. Last, several interviews were conducted with writing instructors to gauge the validity of collected students' responses.

\section{Effective Practices in Writing Classes}

Writing classes have been modernized for decades to include effective means to help students write better. Writing instructors agree that the writing process includes three essential steps: prewriting and drafting, writing, and revision. Each step must be given the same attention as the others, and each step must receive the same weight in the final grade at the end of the semester (see Aaron 2007, Elbow 1998, Kane 1983, Raimes 1983). The following sections will go briefly over the most common methods and conventions used in writing classes in well-established English departments, especially in the United States, compared to the current situation in most regional universities.

\section{3.a. Prewriting and Drafting}

As mentioned, the writing process has three major steps: prewriting and drafting, writing, and revision, and each step is as essential as the others. Prewriting and drafting is the lengthiest step in the whole process, and this activity often receives the most attention by both students and instructors (See Graham \& Fitzgerald, 2007; Raimes, 1983; White \& Arndt, 1991). Prewriting precedes drafting. It involves choosing a manageable topic, thinking, taking notes, discussing with others, brainstorming, outlining, and gathering information, or any other task students engage in before working on their first draft. The written draft is an early version of a piece of writing and presumably shows the writer's initial efforts to compose and produce a wellwritten statement. Though specialists agree that the writing process involves several distinct steps, it is not always linear. A writer may move back and forth between steps as needed. For example, when revising, a writer may return to the prewriting step to develop or expand details or ideas. The process of drafting itself is thus a back-and-forth activity in which writers are engaged in multiple attempts before they complete the final version of a written text. Freeman (1987) describes the process of drafting as follows:

Composing is not a linear process: first, think; second, plan; and third, write-as it has been described-but rather a recursive one. Writers begin to write, they stop, go back, reread what they have written and naturally even revise it before resume writing. (p. 2)
Since a draft reflects a writer's initial attempts to communicate a certain meaning, student writers are often told that the chief aim of drafting is to jot down ideas and meaning and that they should ignore writing mechanics or any other surface level errors and imperfections that may disrupt the natural flow of ideas on paper. Elbow (1998) offers the following advice to novice writers:

It is an unnecessary burden to try to think of words and also worry at the same time whether they're the right words... [and] when writing your first draft, just focus on getting the ideas roughly into sentences. Don't worry too much about grammar, spelling, or even ideal vocabulary (p. 54)

Kane (1983) reiterates the same ideas held by others and provided guidelines for student writers engaged in the process of drafting:

A draft is not the final product: it is by nature rough and imperfect.... Your primary goal is to develop ideas, to work out a structure. Do not lose sight of these major goals by pursuing minor ones-proper spelling, conventional punctuation, the exact word. These come later. (p. 13)

Such ideas have become the guidelines for students and instructors to consider in the process of drafting. Competent writing instructors consider drafting an activity that all students must be engaged in before writing their final version. Equally important, in-class drafting is often sustained by two other activities: group cooperative writing technique and teacher-student conferences.

\section{3.b. Group Cooperative Writing Technique}

The process of drafting can be also carried out by engaging students in what is called the group cooperative writing technique, a technique that has been used for decades in well-structured writing programs and has been proven effective in garnering student writing skills (see Alvarez, Espasa, \& Guasch, 2011; Kegan, 1994; Fassler, 1978; Kane, 1983; Louth, McAllister, C \& McAllister, H. A, 2011). This technique creates an inspiring environment and interaction necessary for enhancing student engagement in the writing process. It promotes selfconfidence and low levels of anxiety, and it offers opportunities for students to produce better writing. Burton (1981) describes further advantages of this activity. He sees the idea of having students work as a group encourages the exchange of ideas on both content and form of their writing. In addition, teamwork creates an unspoken competition within the group and a motivation to work harder and write better or at least to write the way others do. Dixon (1986) one of the earliest advocates of 
group cooperative writing technique, describes other value to student group work:

The first value [of teamwork] for the student is that their writing is being read by real readers and not just falling under the jaundiced eye of the teacher. The fact that students know that readers other than the teacher will be reading their writing is often enough to stimulate them to reread and revise what they have written. Second, by using this technique, students become critical readers not only of others' works, but of their own. (p. 4)

The role of instructors is of great importance when students engaged in the group cooperative writing technique. Instructors are expected to motivate students to participate in such activities and explore their topics fully with the group. When groups meet, instructors often emphasize repeatedly the idea that the focus in prewriting or drafting is on the content and the process itself; meanwhile students are encouraged to freely express and put in writing their ideas without the inhibitions of surface errors or peer critique. In addition, instructors may provide the needed terminology and a checklist of questions for students to use in peer conferencing activities and in responding to and commenting on peer drafts (Stokes, 1984).

\section{3.c. Teacher--Student Conferences}

The process of drafting can be also improved through teacher--student conferences. Such conferences have been widely used by writing instructors at well-reputed universities, and their effectiveness has been proven. Conferences are usually held on a regular basis during the drafting process, while working on the final version, or even before or after revision. Research on the writing process suggests that writers learn more about writing when they share and reflect on their writing with peers or instructors (see Anderson, 2000; Graham, MacArthur, \& Fitzgerald, 2007; Graves, 1982). In classrooms or in their offices, instructors may hold private conferences with individual students. Whether the conferences occur with pairs, small groups, or individually, the sharing of writing contributes significantly to the improvement of student skills. Conferences offer a nonthreatening audience of peers and the instructor. Peers or the instructor can provide immediate feedback, which may promote positive attitudes toward writing and hone student motivation to write better. Students can also be exposed to a wide range of writing abilities and topics. During conferences, competent instructors capitalize on students' strengths, point out areas to be improved, and provide some guidelines and feedback to show students ways to convert their drafts into coherent written statements. Teacher- student conferences are also valuable because they help students recognize the effect of their writing on readers; this effect may remain unnoticed otherwise. Fassler (1978), based on her long experience of teaching writing courses, regards such conferences as greatly important to both instructor and students:

Private conferences are better than red ink, because they allow the teacher to give more feedback, because they increase the teacher's concentration and pace, because they demystify for students the evaluating process, and because they facilitate a more personal, and a more real teacher-student interaction. (p. 190)

Teacher feedback should include suggestions instead of direct questions, for the goal of conferencing is to help students respond more positively and revise more effectively without the threat of red ink correction. Needless to say, having student papers extensively marked in red, whether marks are conspicuous or essential, can offend or be discouraging to students and may to a great extent hamper the creativity and confidence needed in the writing process. During amicable conferences, instructors can give advice, so students can reconsider their writing without the presence of inhibiting red slashes all over their written statements. Instructors' congenial comments are more likely to be taken by students as extra effort to help improve their writing rather than to expose their weakness.

\section{3.d. Engagement of Students in Correcting Activities}

Teacher-student conferences have another value. During conferences, experienced instructors engage students in the process of correction. Specialists agree that engaging students in the correction process is more effective and less likely to offend studentsthan the traditional mystifying evaluation process that traditional instructors use. Careful guidance may help willing students see their errors and revise with the help of both instructor notes and a reference book. Sekara (1988), who favors student selfcorrection, affirms, "There is no denying that students learn and learn more meaningfully and effectively if they are actively involved in the task at hand" (p. 8). To achieve effective self-correction, students are often advised to use a checklist prepared by instructors, or they might be referred to a handbook to consult. Furthermore, a wellorganized folder, where students keep corrected papers with drafts and revisions, is a helpful resource to draw upon in evaluating their own writing. Students may compare their new and old writings, making use of all the observations and marginal notes instructors have provided on previously written and corrected versions. Going back to their old pieces may help students recognize and easily admit the defects in need of revision.

\section{3.e. Writing the Final Version}


After a long process of prewriting and drafting; adding, deleting, and rearranging ideas, and freeing the draft from all the errors, students are asked to compose a final draft. As a tradition embraced by competent instructors, this version is always written in class. Out-of-class writing is rarely recommended, regardless of the circumstance. No excuse is accepted, and tardiness or late work is often penalized by at least one letter grade. This practice is strictly observed in the writing of paragraphs and short essays, but not in long essays or research papers, which are usually done out of class.

\section{3.f. Revision}

Like drafting, a systematic revision is critical in writing classes (Faigley \& Witte, 1981). Students are required to revise their papers based on the notes and observations instructors put on their written work. This is considered an imperative stage, when a draft is viewed thoroughly and points incorporated in the draft are rearranged. Revision is likewise "the crucial point ... when discovery and organization come together, and when writers refine and recast what they have written and shape it into a coherent written statement" (Taylor, 1981, p. 7). It is an essential part of the process of writing, and it gives an ample opportunity for students to add to and rearrange their writing, and to remove and replace portions of it. This is the time to refine and recast what is already written. New details might be added, and others might be removed and replaced based on instructors' comments. Revision should not be limited to mere editing, but it should cover all aspects of composition. Faigley and Witte (1981) recommend that revision should include surface and meaning changes (p. 402). Surface changes are of two types - formal changes and meaning-preserving changeswhereas meaning changes comprise two categoriesmicrostructure and macrostructure changes that may affect the meaning of the text in varying degrees. In practice, what needs to be revised depends on the instructors' judgment and suggestions indicated in comments and editing marks on the draft. Thoughtful comments and marginal notes are carefully generated to avoid killing the voice of writers or thwarting their expectations and likely undermining the main purpose of revision. Revision is preferably carried out in class under the supervision of the instructor. Students, having their instructor, classmates, and a handbook or a checklist at hand, can attentively and carefully revise their papers, correcting all the errors and eliminating defects, using the marginal comments of their instructor as guidance. Equally important, instructors can more likely motivate students to take the process of revision seriously. To do so, instructors make it clear to students that good revision improves their grades and bad revision will likely backfire. Instructors go over and evaluate student revisions and preferably reconsider the grade assigned before. The same process is repeated for all the written assignments. In an essay writing course, at least five types of essays are generally required, including narrative, descriptive, expository, process, cause-andeffect, compare-and-contrast, and argument. The leading idea in writing classes embraced by most competent instructors is the more students write, the better they get.

\section{3.g. Teacher Feedback}

As a common courtesy, instructors' marginal notes and comments should be carefully generated. The feedback instructors supply presumably helps students work out their revisions better. Instructors are expected to mark only the most offending errors and defects and overlook others. They provide, as well,inspiring comments to help students better revise their papers (see Alvarez, Espasa, \& Guasch, 2011; Zeigler, 1989). Competent instructors do not assign a grade on preliminary drafts to avoid discouraging especially the poorly skilled students. Instead of assigning a disappointing grade, instructors use encouraging comments even on the very poorly written texts. "Good try, promising, need more work, need more details," and so on, are best early on. Equally important, instructors usually match their comments to the level of the writer. For good writers, instructors focus on the refinement of language, improvement of details, organization, unity, coherence, and adequate development. For poorly skilled students, competent instructors focus on minor issues such students can handle-sentence level and paragraph level issues, some but not all errors of writing mechanics, incorrect words and structure, and easy corrections - and leave the rest for the next trial. Exercises from the textbook or the handbook are usually assigned according to the needs of the individual student. More importantly, in responding to students' writing, instructors find effective means to engage students in the process of revising. To do so, instructors may write a code next to the place to be revised matching the codes in the adopted writing handbook or accepted style guide. If no handbook is used, instructors may resort to correction symbols, provided all students are fully aware of those symbols. Guided by the codes or symbols marked on the text, a student can go directly to the checklist or the handbook to correct the marked errors. Without handbooks, style guide, or checklist, students would be at loss, without a model to go by. Minor issues like misspellings and some, but not all, grammatical mistakes can be handled without a handbook, but issues like disagreement, fragments, thesis statements and topic sentences, dangling modifiers, awkwardness, faulty construction, and the like cannot be handled without a reference book. 


\section{3.h. Grading}

Determination of the final grade is generally not only the final version submitted to instructors to evaluate; drafting and revision, as documented in a proper folder or portfolio, are equally important, as are other important matters, such as punctuality, commitment, and the progress a student shows by the end of the semester. All these are factors to be considered when assigning the final grade. Specialists insist that the final grade should reflect the progress students achieve by the end of the semester, not the average of grades they earn for the earliest and the latest sessions of writing (see Belanoff \& Dixon, 1991; Graham et al., 2007; Graham \& Sandmen, 2013). Some poorly skilled students may suffer from considerable disadvantages at the beginning of the semester; however, they may show notable improvement throughout the semester and thus the final grade should reflect the progress they attain. Equally important, on the final exam, student writing proficiency is tested against writing itself, not against surface level errors, grammar exercises or punctuation. A sizable piece of writing should suffice. This final piece may help instructors assign the final grade, especially in uncertain cases, provided a student's performance in the final exam is not considered the main factor in deciding the final grade. It is only one of many aforementioned factors.

\section{3.i. Handbook}

Writing handbooks are commonly used in US universities, and writing instructors in a department generally agree on a single handbook to use. Traditionally, each English department or writing clinic adopts a handbook selected from the many available on the market, to name but a few commonly used, The Bedford Handbook for Writers, Simon \& Schuster Handbook for Writers, New English Handbook, and Prentice Writing Handbook. Most writing handbooks cover the most important aspects of composition, style, grammar, and punctuation. They cover most smaller units (sentence level issues) as well the larger units in the process of writing. Handbooks are fashioned in a way to make it easy for students to go back to a specific section for consultation when drafting or revising. When correcting student papers, instructors may call attention to a specific convention or a general rule, using either the code numbers of errors or agreed upon symbols, so that students may directly locate the appropriate section in the handbook and revise accordingly. Using a handbook is of notable advantages for both instructors and students. In practice, errors detected in students' writing are numerous and cannot all be covered in class. Student errors are various and likewise vary from one student to another. Thus, there is no point in discussing a concern that has already been mastered by the rest of the students except a few of them. Instead, instructors can refer students in need to specific sections to learn about the type of errors and revise.

\section{3.j. Documentation of Students' Writing}

Language departments agree on the importance of documentation, particularly in writing classes. For instance, in most American universities, writing folders or portfolios are a must and are often designed by the department. Most highly qualified instructors hold that a major advantage of portfolios or folders is that they integrate good assessment and good teaching practice tools (see Belanoff \& Dickson, 1991; Domina, 1994; Yancey, 1992; Yancey \& Weiser, 1997). In line with such assumptions, folders or portfolios, whether plain or more elaborate, are always there; they are a major requirement where students document all their writing activities. Every piece of written work-drafts, final versions, or revisions - must be carefully and neatly documented in a department-designed folder or portfolio. As a common tradition, after students turn in their assignments, instructors examine their work, respond to it, sign and date it, and then give it back to students to keep in their folders. By the end of the semester, the folder should contain all the semester writing activities, and students are fully aware that any missing piece of writing may result in consequences for their overall grade. Furthermore, these folders are always left with instructors during the semester and are given to students only when they upload newly written assignments. At the end of the semester, all folders are collected and stored at the department, for they are considered property of the department. This last procedure is observed to avoid duplication of the folder or use of it by other students at a future time.

\section{Failings in Regional Writing Classes}

As the collected data reveal, most instructors in our region are either unaware of the method and techniques used in teaching writing, or they are familiar with, but some obstacles hinder their attempts to apply them. Some instructors claim that they are familiar with the new methods, but don't use them for two notable reasons. First, writing classes are often overcrowded; and second, the instructors themselves are overburdened. The first might be true at public universities, but is not necessarily true at most private universities, where the number of students enrolled in each section ranges between 25 and 30, except for very few cases in crowded English departments. Whether instructors are right or wrong, poor writing skills 
are a reality no one can deny. This deficiency is undoubtedly a consequence of ineffective methods used in writing classes. As students' testimonies reveal, the main concern to many instructors is the final product at the expense of the other two essential steps in the process: prewriting and drafting, and revision; hence, poor teaching practices unfortunately prevail. Added to this, the sole concern of most instructors is surface errors, grammar, misspellings, punctuation and the like. Practices, as such, give a wrong impression to students. Students may think that good writing is a matter of mastering writing mechanics only and in that obtaining a high grade depends only on a student's ability to produce a text free of any misspellings, grammatical mistakes, and misuse of punctuation. Holistic issues such as coherence, adequate development, and unity are given the least of attention and the least weight in grading. In addition, instructors' responses to student writing are mostly general, vague, and unsystematic, and vary from one instructor to another. Overall, strategy is absent. Each instructor uses her/his own plans and measures of assessment without cooperating with others. Hence, the problem persists and calls for serious reform.

To many regional instructors, writing is a product, not a process. The three-fold process is thus reduced to only one step: writing. Modern means and techniques are mostly missing. Moreover, many instances show that students spend more time listening to their instructors speak theoretically about writing mechanics, structural issues, and further theoretical instructions, leaving the actual practice of writing for the exam time. Sometimes writing itself is only a minoror equal part of the exam to questions on grammatical issues, punctuation, and theoretical concerns. For example, definitions of thesis statement, topic sentences, features of a good essay or paragraph, conventions of punctuation, importance of details, and so on are theoretically elaborated in classes, and thus become the points to be tested on in exams. Most instructors seem to overlook the idea that all these issues can be tested through written statements generated in writing sessions, and writing is a matter of applying rather than merely memorizing the rules or conventions.

Another factor that might lead to the same undesirable outcome is the likelihood that writing classes tend to be assigned to newcomers with relatively simple experiences in teaching, and, worse, without specialization in writing. Being uninformed and inexperienced, such instructors handle writing classes the way they do other classes. Most suggest few topics for students to choose from and then leave students on their own to write the way they please. As well, to junior instructors, the final grade often depends on the mastery of writing mechanics, definitions of certain terms, error analysis, and some simple writing exercises. Students manage easily on the theoretical part of the exam by depending on memorization, but they suffer on writing exercises, so deficiencies persist in writing classes.

\section{Findings and Recommendations}

The present study reveals a serious breach with the common conventions customarily employed in teaching English composition. To help rectify the undesirable teaching condition,this study is inclined to showcase the findings elicited, andoffer the following recommendations for composition instructors and administrators to take into account:

\section{5.a. The Number of Enrolled Students}

In our region, most writing classes at public universities are overcrowded. Each section holds between 35 to 45 students and in some cases the number goes above 50 . These crowded classes can also be seen to a lesser degree in private universities. Such numbers of students place a terrible burden on instructors and make it almost impossible to practice all the necessary activities or apply the highly recommended techniques. The instructors may avoid reading or monitoring and responding to all students' drafts, and their role may be reduced to only answering questions raised by students during the drafting or writing sessions. To implement all the essential steps of the writing process, the number of students enrolled in each section should be strictly controlled byEnglish departments, and in any case the number should not exceed 25 students. This relatively small number gives instructors a better chance to carefully read and respond at ease to students' work. With this number, the instructors may have more time to review under less pressure. At the same time, it may also give students enough time to read and share comments on their classmates' work and receive feedback on their own written pieces. Crowded writing classes are not recommended even at less competitive universities. Specialists, are concerned that students' opportunity to receive instructor and peer feedback on their work might be lost in classes with high numbers. This problem can be easily solved by administrators putting restrictions on enrollment numbers as well as restrictions on prerequisites required to attend writing classes, and preferably scheduling one writing section to each instructor per semester.

\section{5.b. Drafting, Writing, and Revision}

The collected data for the present study reveal a serious breach with these common conventions. The three essential activities, drafting, writing, and revision are not given their due importance in our regional universities. 
Prewriting and drafting are done mostly at random. Often students work on their own, beginning the process of writing with a rough draft or writing the final version without, since many instructors do not press the importance of prewriting or drafting nor require students to keep their drafts in folders. Drafting is often done haphazardly; and worse, students are often left alone to begin their rough drafts or even leap directly into writing the final version, as most instructors do not bother collecting student rough drafts or systematically monitoring the drafting process. The collected data show also that sometimes a suggested topic is given to students for homework; and as expected, students write their papers wherever they please: at home, at the library, and at other places. Out of class writing leaves more room for plagiarism, including copying somebody else's writing or having someone else write a paper, considering that such practices cannot be detected, especially in overcrowded classes. In truth, plagiarism is widespread, and often goes unnoticed.

The aforementioned breach might also be true when it comes to revision. Many instances in the collected data show that a considerable number of instructors ignore completely the importance of revision, or at best they do not press it.As a common practice, instructors suggest a few topics for students to pick from and then give the goahead to write. Revision is available for students to rewrite their graded papers (or not); and because revision has no effect on the assigned grades, students do not bother engaging themselves in this unrewarded activity.

To help develop student writing skills, the three essential steps, drafting, writing, and revision must be strictly observed by administrators and taught systematically by instructors. To motivate students to engage in the threestep-process, instructors should make it clear to students how these steps count negatively or positively in deciding their final grade. Without pressing the process as a whole, not only the product, student writing skills would remain unfortunately the same.

\section{5.c. Teacher/Student Conferences, and Teamwork}

Regardless of the importance of such activities, the collected data reveal that neither teamwork nor teacherstudent conferences are used in regional writing classes, except in very few rare cases and not necessarily on regular basis. Most interviewed instructors hold that large numbers of students in their sections present an obstacle to such activity. They admit to the importance of private conferences, but they rarely practice it with their students. They claim that it is not easy to schedule conferences with each student in overcrowded classes. Besides, they feel overburdened with different responsibilities, and this reality makes it hard for them to find time to discuss individual students' writing on regular basis. It is true that teacher-student conferences are not easy to handle in packed classes, but teamwork can be a helpful technique appropriate for large classes (see Dixon 1986; Johnson, R.T. \& Johnson, D.W, 1984). The number of students is not always a valid excuse for overlooking essential activities in the process of writing. Other instructors claim that teamwork may increase hard feelings within groups and lead to some setbacks instead; thus they refrain from using it. Teacher- student conferences are done only when students complain about the grade they receive on their papers. In other words, most instructors are willing, especially at private universities, to go over papers only to justify the grade they assign. Considering the effectiveness of such conferences in attaining the main objectives of writing courses, the academic administrators must capitalize on the significance of Teacher/Student Conferences, and Teamwork.

\section{5.d. Documentation of Student Writings}

Regardless of the importance of documentation of student writing, the collected data reveal that student writing is rarely documented. Some instructors treat student writing papers as they treat exam papers. They collect the papers, correct them, assign a grade on each, and then give them back, leaving it up to students to keep or discard their written work. Well-designed or even plain folders are rarely required. Using a folder is strongly recommended, no matter how plain it is. Using a folder is common in well-organized writing classes. Documentation has been shown to be an important part of writing instruction since the introduction of the practice in the early 1970s. It is a good teaching tool helpful to both instructors and students. On the one hand, writing folders provide instructors with solid evidence to rely on to fairly assess and evaluate student written work during the whole semester. On the other hand, students themselves would have a record and a reference to turn to and more possibly find ways to eliminate the recurring errors in their writing. Upon such observations, the issue of documentation of student writings must be pressed and monitored by academic administrators and instructors.

\section{5.e. Importance of a Reference or a Writing Handbook}

Despite the importance of a reference book, the collected data reveal thatthe overwhelming majority of instructors have not used a handbook in regional writing classes. Ironically, many instructors are completely unaware of the importance of a writing handbook, and no evidence of using such valuable books. Such references are needed, particularly for revision. Handbooks provide students with many examples helpful in handling the common defects in 
their writings. They supply comprehensive examples and explanations for most conceivable errors encountered in freshman, sophomore, and even junior writings. Students cannot manage especially in revision without a handbook. When using a Handbook, the instructor can save time and efforts. Two related factors should be recalled here: first the errors detected in students writing are numerous and cannot be all covered in class; and second, student errors are various, and likewise their needs vary from one student to another. Thus there is no point in discussing a concern very few students need, yet already mastered by the rest. Instead, the instructor can refer students in need to specific sections in the adopted handbook to consult and then recognize the type of errors and revise. The use of a handbook, or at least a well-compiled checklist, is highly recommended to help improve writing teaching methods.

\section{5.f. Correcting and Evaluating of Student Work}

The collected data reveal that the process of correcting and evaluating student writing is carried out only by the instructor. In many cases, instructors fill the paper with red ink, sketchy notes, and a grade, leaving students potentially unclear on the grading's rationale. Checklists, resource books, and writing handbooks are rarely available for students to consult and see what is right or wrong with their work. Due to these observations, grading in writing classes should be reconsidered also. Since instructors agree that writing is a gradual process, nurtured throughout the whole semester, the final grade should reflect the progress students achieve or the writing skills they showcase by the end of the semester. Using the traditional calculation in assigning the final grade is erroneous and should be reviewed. The progress and commitment of students to the rules must be weighed heavily when it comes to final grades. As well, writing skills must be tested only through writing itself, not through exercises on grammar and vocabulary or punctuation conventions. Even on the final exam, a piece of writing of a reasonable size is best instead. As well, the final exam should be given the same weight as other written statements and other aforementioned factors.

\section{CONCLUSION}

Traditional methods used in writing classes will remain ineffective and fail to fulfill their objectives unless the administrators and instructors embrace new practices commonly adopted and used in most American and Western universities. Administrators should also strictly monitor the number of students enrolled in each section of writing courses. Equally important, assigning one writing section per semester to each instructor would lessen the pressure and give more time for teachers to engage students in many helpful practices. Useful practices must be applied, including teacher-student conferences, teamwork, teacher feedback and inspiring comments on student writing, and the like. Finally, instructors should keep in mind that writing is a process, not a product. Consequently, each step in the process must be given its fair share of importance and attention. In addition, dedicated writing instructors should embrace the idea that encouragement and patience are keys in writing classes. Without these, instructors will fail to achieve the main objectives of writing classes and hence breach their obligations.

\section{REFERENCES}

[1] Aaron, J. E. (2007). The Compact Reader. New York, NY: Macmillan.

[2] Anderson, C. (2000). How's it going? A practical guide to conferring with student writers. Portsmouth, $\mathrm{NH}$ : Heinemann.

[3] Alvarez, I., Espasa A., \& Guasch, T. (2011). The value of feedback in improving collaborative writing assignments in an online learning environment. The Journal of Educational Research, 104(6), 387-400.

[4] Belanoff, P., \& Dickson, M. (Eds.) (1991). Portfolios: Process and Product. Portsmouth, NH: Boynton/CookHeinemann.

[5] Bullock, Richard., Michael Brody., \& Francine Weinberg. (2016). The Little Seagull Handbook with Exercises. 3rd edition. New York: Norton \& Company.

[6] Elbow, P. (1998). Writing Without Teachers (2nd ed.). Oxford, UK.: Oxford University Press.

[7] Burton, A. S. (1981). A decision-making approach to the extended writing lessons. ELT Journal, 35(2), 141-146.

[8] Dixon, D. (1986). Teaching Composition to large Classes. English Teaching Forum, 24(3), 2-13.

[9] Domina, L. (1994). The body of my work is not just a metaphor. In W. Bishop \& H. Ostrom (Eds.) (1994) Colors of a different horse. Urbana, IL: National Council of English Teachers. (27-34).

[10] Faigley L.,\& Witte, S. (1981). Analyzing Revision. College Composition and Communication, 32(4), 400-414.

[11] Fassler, B. (1978). The red pen revised: Teaching composition through student conferences. College English, 40(2), 186-189.

[12] Freeman, D. L. (1987). From unity to diversity: Twentyfive years of language-teaching methodology. English Teaching Forum, 25(4), 2-9.

[13] Gleen, Cheryl., \& Loretta Gray. (2012). The Hodges Harbrace Handbook, 18th edition. Belmont, CA: Wardsworth Publishing.

[14] Graham, S., MacArthur, C. A., \& Fitzgerald, J. (Eds.). (2007). Best practices in writing instruction. New York, NY: Guilford Press.

[15] Graham, S. \& Sandmen, K. (2013). The process writing approach: A meta-analysis. Journal of Distance Education, 34(3), 396-407. 
[16] Graves, D. (1982). Six guideposts to a successful writing conference. Learning, 11(4), 76-77.

[17] Guasch, T. and et al. (2012). Effects of feedback on collaborative writing in an online learning environment. Studies in Higher Education, 37(4), 324-338.

[18] Johnson. T. \& Johnson, D. W. (Eds.). (1984). Structuring cooperative learning: Lesson Plans for Teachers. Minneapolis, MI: Interaction Book Company.

[19] Hacker, Diana., \& Nancy Sommers. (2013). The Bedford Handbook for Writers, 9th edition. Boston, Mass: St. Martin's.

[20] Kane, T. S. (1983). The Oxford guide to writing. Oxford, UK: Oxford University Press.

[21] Kagan. (1994). Kagan Cooperative Learning. San Clemente, CA: Kagan Publishing.

[22] Louth, R., McAllister, C., \& McAllister, H. A. (2012). The effects of collaborative writing techniques on freshman writing and attitudes. Studies in Higher Education, 37(4), 215-224.

[23] Nunan, D. (1997). Research Methods in Language Learning. Cambridge, UK: Cambridge University Press.

[24] Raimes, A. (1983). Techniques in Teaching Writing. New York, NY: Oxford University Press.

[25] Sekara, A. T. (1988). A student-centered report writing program. English Teaching Forum, 26(2), 8-11.

[26] Reid, Stephen R. (2013). The Prentice Hall Guide for College Writers, 10th edition. New York: Pearson.

[27] Sommers. N. (2012). Responding to student writing, In I. L. Clark (Ed.), Concepts in Composition. New York, NY: Routledge.

[28] Stokes, E. (1984). An ESL Writing Workshop. TESOL, Newsletter, Vol. 18, No. 4-15

[29] Taylor, B. P. (1981). Content and the Writing Form: A twoway street. TESOL Quarterly. 15 (1), 5- 13.

[30] Troyka, Lynn., \& Doug Hesse. (2017). Simon and Schuster Handbook for Writers, 11th edition. New York: Pearson.

[31] White, R., \& Arndt, V. (1991). Process of Writing. London, UK: Longman.

[32] Yancey, K. B. (Ed.). (1992). Portfolios in the writing classroom: An introduction. Urbana, IL: National Council of Teachers of English.

[33] Yancey, K. B. \& Weiser, I. (Eds.). (1997) Situating portfolios: Four perspectives. Login: Utah University Press.

[34] Ziegler, A. (1989). Midwifing the craft-Teaching revision and editing. In J. M. Moxley's (Ed.), Creative Writing in America (209-225). Urbana, IL: National Council of Teachers of English. 